\title{
Critical flow velocities in cohesive saline soils
}

\author{
Sobir Eshev ${ }^{1 *}$, Mahmud Rahmatov ${ }^{1}$, Alisher Khazratov ${ }^{1}$, Nurbek Mamatov $^{1}$, Jasur \\ Sagdiyev $^{2}$, and Mustafo Berdiev ${ }^{3}$ \\ ${ }^{1}$ Karshi Engineering-Economics institute, Karshi, Uzbekistan \\ ${ }^{2}$ Karshi branch of the Tashkent Institute of Irrigation and Agricultural Mechanization Engineers, \\ Karshi, Uzbekistan \\ ${ }^{3}$ Tashkent Institute of Irrigation and Agricultural Mechanization Engineers, Tashkent, Uzbekistan
}

\begin{abstract}
The article discusses the issue of determining non-erosion velocities for cohesive saline soil at the bottom and slopes of canals. Based on the formulas of Ts.E. Mirtskhulava for the determination of non-eroding velocities of water flow in cohesive soils, equations for determining noneroding velocities for cohesive saline soil are proposed. A brief technique for conducting laboratory experiments and modeling of saline soil is presented. Based on the obtained data of laboratory experiments, the dependences for determining the non-eroding velocities of the water flow in the channels of the cohesive saline soils are obtained.
\end{abstract}

\section{Introduction}

Irrigation and drainage construction and operation of canals and collectors in the arid zone of Uzbekistan requires a significant amount of research on the deformation of easily erodible saline soils. Cohesive soils in their thickness contain inclusions of organic-mineral compounds and readily soluble salts. These inclusions cement the rock in dry form and weaken it when it is moistened, causing swelling, soaking, and diffusion leaching of the soil [1-10], [17].

When water enters the dry saline soil, salt in the form of mechanical impurities dissolves. Soil colloids absorb part of the saline solution, part fills the micropores of microaggregates, and the rest of the dissolved salt is removed from the soil by a water flow. At the same time, the resistance of soils to erosion decreases.

According to the content of soluble salts present in soils, the latter is divided into the following groups:

1) readily soluble (chloride, sulfate, carbonate salts of sodium and potassium);

2) medium soluble (calcium sulfates);

3) poorly soluble (calcium and magnesium carbonates).

Salt suffusion, which causes a disturbance in the stability of the soil structure, as a result of which the dissolution of salts and removal from the soil mass, in some cases, is the cause of erosion [3].

\footnotetext{
* Corresponding author: telnets@mail.ru
} 
The amount of salt in the soil is of primary importance in salt suffusion. Its low content does not cause the danger of suffusion deformations during leaching. The high content determines the tendency of the soil to change its properties under the influence of the flow; it is dangerous from the point of view of the development of mechanical suffusion.

The leaching efficiency largely depends on the chemical composition of the salts. For example, chlorides are washed out faster than sulfates due to their easy solubility.

When the soil is saturated with water, the connectivity due to capillary forces disappear, and due to the forces of molecular attraction and the astringent effect of salts, organic matter, and clay minerals decrease. Thus, soil cohesion decreases as it becomes wet.

As a result of a decrease in the cohesion during moistening, the resistance of saline soil to hydrodynamic forces decreases.

During leaching, conditions are created for the shear and transfer of its particles, salt crystals and microaggregates by the flow, that is, for the beginning of mechanical suffusion. Further, the suffusion process develops with the simultaneous action of salt and mechanical suffusion, but the salt suffusion will be less intense.

Thus, the main factor disrupting the stability of the structure of saline soils is the dissolution and removal of salts, that is, salt suffusion, and the main factor in the resistance of saline soils to mechanical suffusion is connectivity, which depends on the degree of leaching [3].

Earthen channels running in cohesive saline soils are also designed using the nonerosion velocity method. There are many dependencies proposed by various researchers to determine non-eroding water flow velocities in non-cohesive and cohesive soils. In practice, when determining the non-eroding velocities of the water flow in cohesive soils for channel design, it is recommended to use the dependencies proposed by Ts.E. Mirtskhulava [17].

$$
\begin{aligned}
& \vartheta_{H}=\left(\lg \frac{8.8 h}{d}\right) \sqrt{\frac{2 m^{\prime}}{2.6 \rho \cdot n}}\left[g\left(\rho_{S}-\rho\right) d+1.25 C_{y}^{n} K\right] \\
& \vartheta_{\Delta H}=1.25 \sqrt{\frac{2 m^{\prime}}{2.6 \rho \cdot n}}\left[g\left(\rho_{S}-\rho\right) d+1.25 C_{y}^{H} K\right]
\end{aligned}
$$

where $d$ is diameter of cohesive soil aggregate; $h$ is flow depth; $m^{\prime}$ is working condition factor; $n$ is load factor; $\rho_{s}, \rho$ arerespectively, the density of soil and water; $C_{y}^{H}$ is fatigue fracture limit of cohesive soils; $K$ is coefficient of homogeneity of cohesive soils.

The author of [17-26] shows more fully the features of the hydrodynamic effect of the flow on the bottom particles and the conditions for the stability of aggregates under the influence of the flow in close connection with the characteristics of the strength properties of the soil.

The non-eroding flow velocities obtained by these formulas for canals laid in cohesive saline soils, depending on the depth of water in the canal, the specific cohesion of the soil, and readily soluble salts' content in it, are given in [27-34].

However, in the proposed formulas (1) - (2), not all soil factors are considered. For example, soil salinity is not taken into account. The design of irrigation canals in Central Asia is associated in a number of cases with the need to take this factor into account. Various water-soluble salts are found in significant quantities in the soils of this region.

\section{Method}


The methodology for preparing cohesive saline soil and conducting experimental studies is described in detail [3].

5 samples of the disturbed structure of cohesive saline soils were studied. After each experiment, to establish the physical and mechanical parameters of soils, they were tested in laboratory conditions.

The destruction of saline soils by water consists of washing off mineral particles from the soil surface and dissolving and removing salts from the soil. As a result, their strength and stability decrease, leading to erosion of canal beds.

The erosion velocities of water flow in saline cohesive soils, as in other soils, are due to many interacting and interrelated factors. These include physical and mechanical properties. These factors include cohesive soils, humidity, moisture capacity, water resistance, cohesion, density, specific gravity, mechanical composition, structure, plastic properties, mineralogical composition. Also, cohesive saline soils are also characterized by such properties as salinity and suffusion properties, water permeability, etc.

The aim of this work is to study the physical and mechanical properties of saline cohesive soils and their influence on the process of erosion of earthen canals. With laboratory experiments, the main physical and mechanical parameters of the studied soil for erosion have been established.

The method of preparing cohesive soil for testing was fully consistent with the methodology of Ts.E. Mirtskhulava, set forth in [17].

Five samples of cohesive saline soils of a disturbed structure were prepared for the study, which was prepared as follows: the first sample of soil was represented by non-saline light sandy loam, and salt solutions with a concentration of $10 \mathrm{~g} / 1$ were gradually added to the rest of the samples; $20 \mathrm{~g} / 1 ; 35 \mathrm{~g} / 1$ and $50 \mathrm{~g} / \mathrm{l}$; the resulting mixtures were thoroughly mixed and subjected to uniform compaction in metal cassettes; cassettes of soil samples were placed in five baths, in which salt solutions of the corresponding concentration were kept and kept for 10-15 days.

Experiments were carried out to establish the physical and mechanical properties of saline cohesive soils, and the results are shown in Table 1.

From table-1, it can be seen that the number of plasticity and the bounds of fluidity and rolling in saline cohesive soils are absent. In this regard, saline cohesive soils are rapidly eroded.

Table 1. Results of experiments to establish the physical and mechanical properties of saline cohesive soils

\begin{tabular}{|c|c|c|c|c|c|}
\hline Soil & $\begin{array}{c}\text { Not salted, } \\
\text { sandy loam } \\
\text { lightweight }\end{array}$ & $\begin{array}{c}\text { Not salted, } \\
\text { sandy loam } \\
\text { lightweight }\end{array}$ & $\begin{array}{c}\text { Slightly salted, } \\
\text { sandy loam } \\
\text { lightweight }\end{array}$ & $\begin{array}{c}\text { Medium salted, } \\
\text { sandy loam } \\
\text { lightweight }\end{array}$ & Highlysalted \\
\hline $\mathrm{W} . \%$ & 12.56 & 13.99 & 14.42 & 14.05 & 14.23 \\
$\mathrm{~V}_{\mathrm{rp}} \cdot \mathrm{g} / \mathrm{cm}^{3}$ & 2.12 & 2.13 & 2.17 & 2.17 & 2.13 \\
$\mathrm{~V}_{\mathrm{ck}} \cdot \mathrm{g} / \mathrm{cm}^{3}$ & 1.88 & 1.86 & 1.90 & 1.90 & 1.86 \\
$\rho_{\mathrm{rp}} \cdot \mathrm{g} / \mathrm{cm}^{3}$ & 2.67 & 2.67 & 2.67 & 2.67 & 2.67 \\
$\mathrm{n} . \%$ & 25.59 & 30.34 & 28.84 & 28.84 & 30.34 \\
$\varepsilon$ & 0.42 & 0.44 & 0.41 & 0.41 & 0.44 \\
$\mathrm{I}_{\mathrm{W}}$ & 0.80 & 0.85 & 0.94 & 0.91 & 0.86 \\
$\mathrm{~W}_{\text {max. } \%}$ & 15.73 & 16.48 & 15.36 & 15.36 & 16.48 \\
$\gamma_{\text {взв }}-$ & 1.18 & 1.16 & 1.18 & -18 & 1.16 \\
$\mathrm{~W}_{\mathrm{T}} \% \%$ & - & - & - & - & - \\
$\mathrm{W}_{\mathrm{p} .} \%$ & - & - & - & - & - \\
$\mathrm{I}_{\mathrm{p}}$ & - & - & - & - & - \\
$\mathrm{I}_{\mathrm{L}}$ & - & - & - & & \\
\hline
\end{tabular}


Mechanical characteristics, i.e. the adhesion force and the angle of internal friction of the soils, were determined by the method of shear resistance under conditions of incomplete compaction with GGP-30 devices of the Maslov-Lurie design (Table 2).

Table 2.

\begin{tabular}{|c|c|c|}
\hline Soil sample & $\begin{array}{l}\text { Adhesion force } \\
\mathrm{C}, \mathrm{kg} / \mathrm{cm}^{2}\end{array}$ & $\begin{array}{c}\text { Internal friction } \\
\text { angle } \\
\varphi\end{array}$ \\
\hline $\begin{array}{l}\text { 1. Non-salted sandy loam light coarse } \\
\text { 2.Non-salted sandy loam light coarse } \\
\text { 3.Slightly salted sandy loam Light } \\
\text { coarse } \\
\text { 4.Medium salted sandy loam light } \\
\text { coarse } \\
\text { 5.Highly salted }\end{array}$ & $\begin{array}{c}0.26 \\
0.052 \\
0.041 \\
0.037 \\
0.018\end{array}$ & $\begin{array}{c}2^{\circ} 18^{\prime} \\
10^{\circ} 12^{\prime} \\
4^{\circ} \\
3^{\circ} 23^{\prime} \\
8^{\circ}\end{array}$ \\
\hline
\end{tabular}

We analyze the results of the experiments. The genesis, structure, connectivity and water properties of saline soils determine the processes occurring when water moves through them. When water enters an absolutely dry saline soil, salt in the form of mechanical impurities dissolves. Soil colloids sorb part of the saline solution, part fills the micropores of microaggregates, and the rest of the dissolved salt is carried away from the soil surface by a water flow.

When the soil is saturated with water, the connectivity due to capillary forces disappears due to the forces of molecular attraction and the astringent action of salts, organic matter and clay minerals - decreases. Thus, soil cohesion decreases as it becomes wet.

Soil soaking takes place differently in water and in salt solutions. The erosion of soils is understood as their ability to give off aggregates and elementary particles to moving water, acting on the surface of the soil layer. This property of soils and the dynamics of water impact determine the soil massif's erosion.

The next one of the main physical indicators characterizing the mechanical strength of cohesive soils is porosity. Their mechanical strength, in conditions where other parameters being equal, increases with decreasing porosity. The plasticity of the soil is called its ability to deform under the action of external pressure without breaking the continuity of the mass and maintaining the given shape after removing the deforming force [3]. The magnitude of the plasticity number is indirectly judged on the degree of clay, physical-mechanical and water properties of the soil. An increase in the clay content of the soil entails an increase in the number of plasticities.

The shear resistance is one of the most important characteristics of the soil, as it characterizes its stability in the slopes and the bottom of the channels.

The shear resistance of clay soils is determined by two indicators: 1) internal friction and 2) adhesion.

Table 2 shows that with an increase in soil salinity, the angle of internal friction decreases, and the adhesion also naturally decreases.

This can be explained as follows. In saline cohesive soils, it was found that with an increase in the salt content in them from 0 to $1.5 \%$, their shear resistance decreases (Figure $1)$. 


$$
\tau, 10^{5} \mathrm{~Pa}
$$

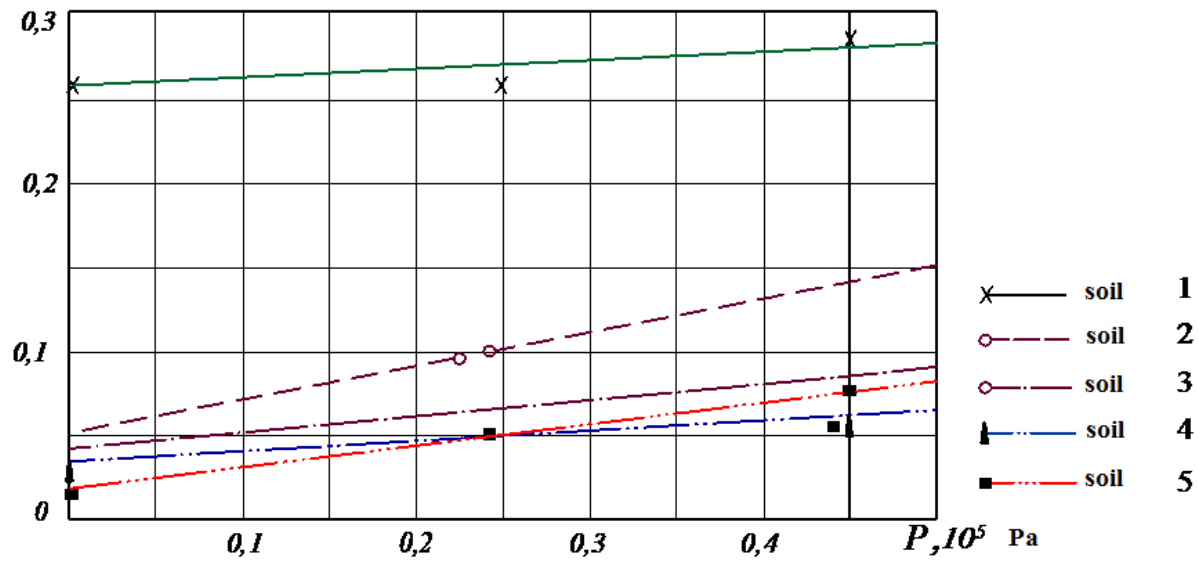

Fig. 1. Ultimate shear resistance of cohesive saline soils

The latter circumstance determines the intensification of the erosion of saline soils. When a water flow passes over saline soils, salts are leached out, and part of them is carried away by the water flow. In this case, the connection between soil aggregates is destroyed, and the erosion of the latter begins.

Thus, one of the main factors affecting the stability of the structure of saline soils is the dissolution and removal of salts, that is, salt suffusion. The main factor in the resistance of saline soils to mechanical suffusion is connectivity, which depends on the degree of leaching.

Therefore, when calculating the erosion of earthen channels in saline soils, it is necessary to carefully study these soils' physical and mechanical properties.

\section{Results and discussion}

We proceed to the hydraulic formulation of the problem of erosion of cohesive saline soils. To consider the salinity of soils when calculating non-erosion velocities, experimental studies were carried out on a hydraulic chute (chute parameters are $13.6 \times 1.0 \times 0.8 \mathrm{~m}$ ). This tray was used to reproduce a model of a trapezoidal channel, which has the following dimensions: length $-8.5 \mathrm{~m}$; bottom width $-0.30 \mathrm{~m}$; height $-0.15 \mathrm{~m}$, slope placement $-m=2$.

On the slopes and at the bottom of the canal, nests for metal cassettes with dimensions of 0.33 x $0.15 \times 0.10 \mathrm{~m}$ were arranged on the slope $0.30 \times 0.15 \times 0.10 \mathrm{~m}$ in the central part of the bottom of the canal. The studied cohesive saline soils were placed in the cassettes.

The results of the carried out experiments are summarized in table 3. In saline cohesive soils, it was found that with an increase in salt content from 1.5\%, their shear resistance decreases (Fig. 2).

The latter circumstance determines the intensification of the erosion of saline soils (Fig. 3). When the water flow passes over saline soils, salts are leached out, and some of them are carried away by the water flow. In this case, the connection between soil aggregates is destroyed, and the erosion of the latter begins. 


\section{$\mathrm{C}, 10^{5} \mathrm{~Pa}$}

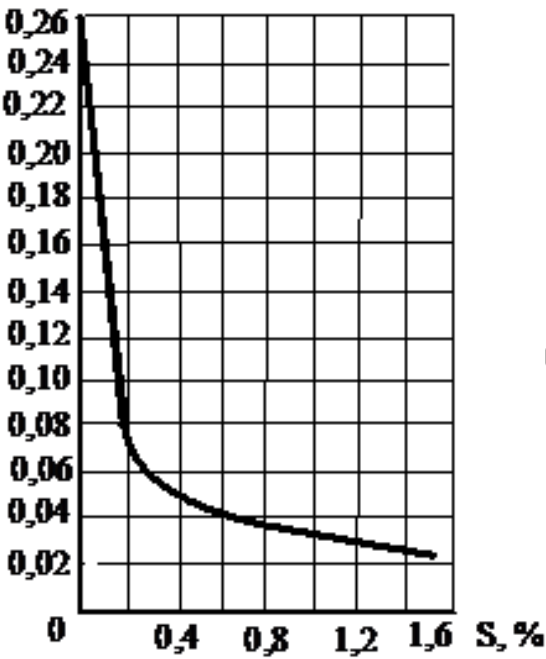

Figure. 2Diagram of $C=f(S)$

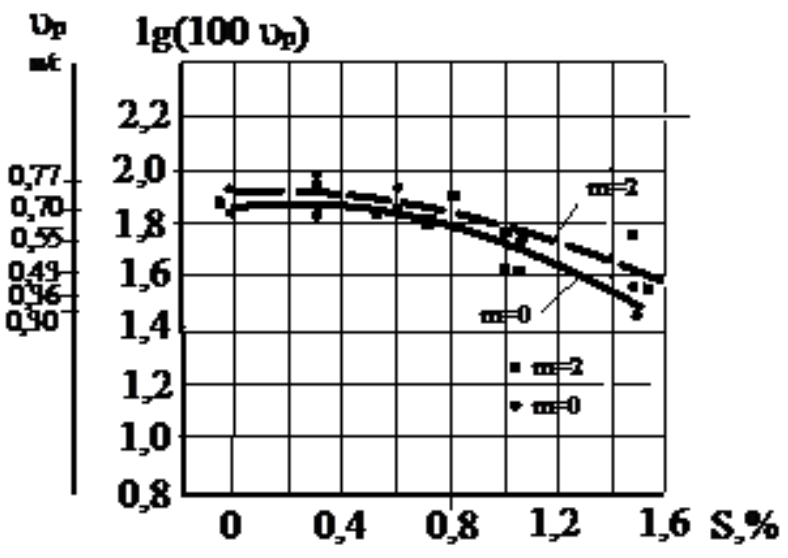

Figure. 3Diagram of $\vartheta_{P}=f(S)$

For cohesive saline soils, there is a used assumption that coefficient $a$ is equal to 1,25 in equations (1) - (2) accepted to be dependent onthe salinity of soils (Figure 4).

From the given figure 4, 3.11 is clear, that in interval $0<\mathrm{S} \leq 0.6 \%$ - value of coefficient " $a$ " rapidly increases, in interval $0,6 \%<\mathrm{S} \leq 1.5 \%$ - decreases. In this maximum value of " $\boldsymbol{a}$ " corresponds to salinity of soils $\mathrm{S}=0.6 \%(a \approx 2)$, that is value of " $a$ "increases approximately 5 times when $\mathrm{S}=0(a \approx 4)$.

The above circumstance dictates the need to consider when calculating the non-eroding velocities of saline soils, which is carried out by introducing the calculated dependence of the coefficient "a". Then dependences (1) and (2) will finally take the following form for cohesive saline soils:

$$
\begin{aligned}
& \vartheta_{H}=\left(\ell g \frac{8.8 h}{d}\right) \sqrt{\frac{2 m^{\prime}}{2.6 \rho n}\left[g\left(\rho_{S}-\rho\right) d+a C_{y}^{H} K\right]} \\
& \vartheta_{H}=1.25 \cdot \sqrt{\frac{2 m^{\prime}}{2.6 \rho n}\left[g\left(\rho_{s}-\rho\right) d+a C_{y}^{H} K\right]}
\end{aligned}
$$

It should be noted that erosion in trapezoidal canals passing through saline cohesive soils is observed almost simultaneously in the central part of the canal and on its slopes. Therefore, dependencies (3) - (4) can be used to determine the non-eroding velocities of water flow in cohesive saline soils, both for the central part of the channelwith the greatest depths) and for the slopes.

From table 3, it is clear thatwith the increase of $B / h$ ratio, $a^{\prime \prime} / a^{\prime}$ ratio decreases. Given the analysis of experimental data describes dependencies between $B / h$ and $a^{\prime \prime} / a^{\prime}$ ratios, which shows the existence of connections between these two parameters (Figure5). 
Table 3.

\begin{tabular}{|l|l|l|l|l|l|l|l|l|l|l|}
\hline$B / h$ & 6 & 7 & 8 & 9 & 10 & 11 & 12 & 13 & 14 & 15 \\
\hline$a^{\prime \prime} / a^{\prime}$ & 1.65 & 1.35 & 1.175 & 1.025 & 0.91 & 0.825 & 0.775 & 0.725 & 0.7 & 0.675 \\
\hline
\end{tabular}

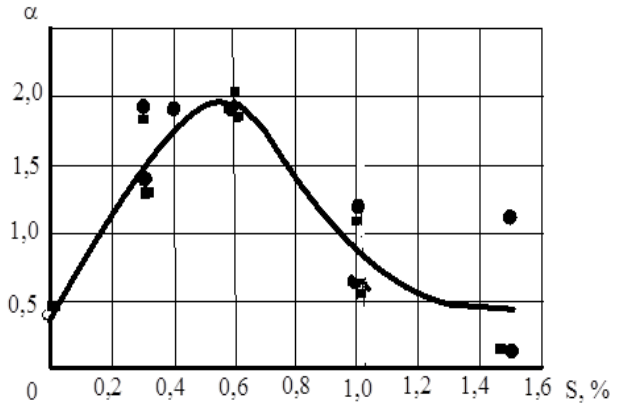

Fig. 4. Diagram of $a=f(S)$

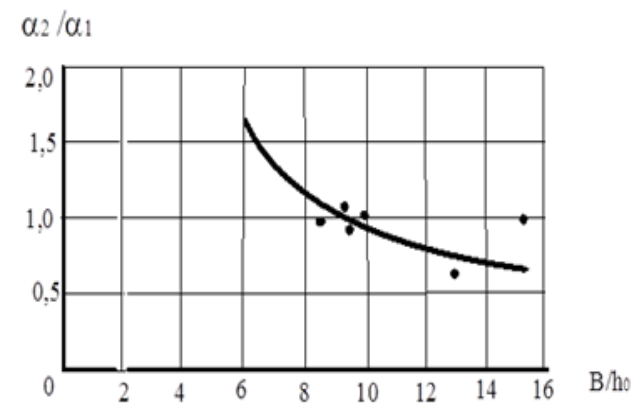

Fig. 5. Diagram of $a_{2} / a_{1}=f(B / h)$

A comparison of the experimental data in saline soils with the calculated dependence (5) is shown in (Fig. 6), and their values are summarized in Tables 3.
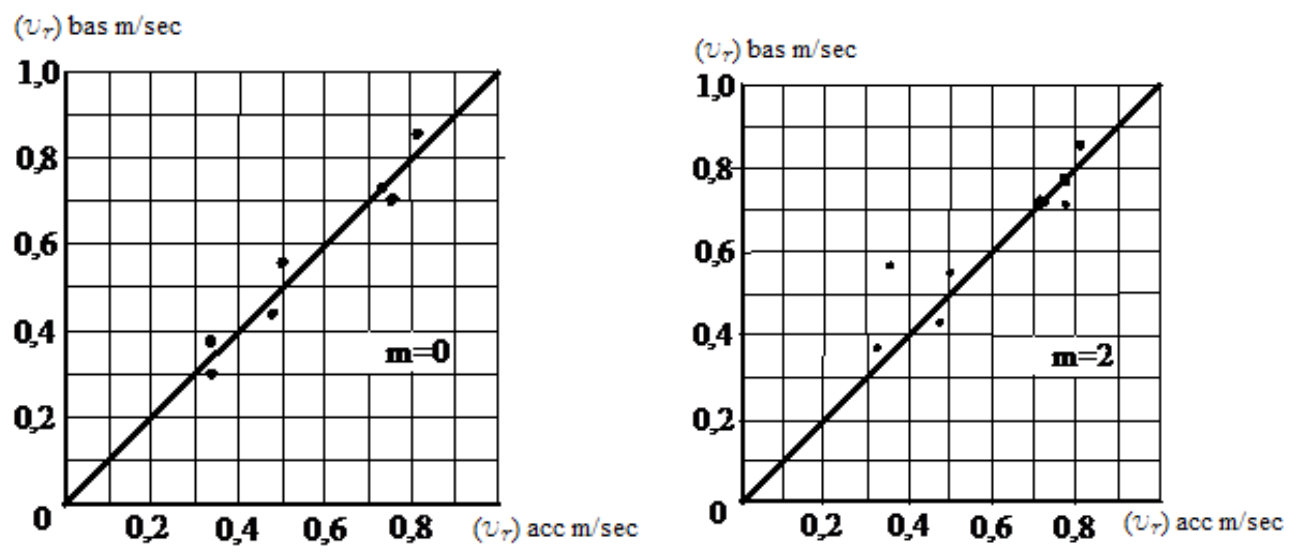

Fig. 6. Comparison of non-eroding velocities in cohesive soils obtained from experiments with calculated values

\section{Conclusions}

So, the proposed dependencies (3) - (4) can be used to establish non-eroding water flow velocities in cohesive saline soils. In this case, the coefficient taking into account the salinity of soils " $\boldsymbol{a}$ " is determined from (Figure 4), depending on the percentage of salt in the soil. To determine the values of non-eroding velocities on the slopes of the channel, it is recommended to introduce a correction for the relative width of the channel. 


\section{References}

1. Abalyants S.Kh. Stable and transient regimes in artificial channels, Leningrad Gidrometeoizdat, p. 239, (1981)

2. Vysotsky L.I. About the concept of "equivalent roughness, Izv. Universities, Construction. № 12, pp. 98-101, (2004)

3. Eshev S.S. Calculation of deformations of large earth canals under conditions of stationarity of the water flow. Tashkent, p. 164, (2017)

4. Borovkov V.S., Hydraulics of water and suspended streams in rigid and deformable boundaries, Moscow, ASV Publishing House, p. 260, (2009)

5. Debolsky V.K. To the study of the erosion rates of the channel flow. - Proceedings of MIIT, p. 319, pp. 78-87, (1968)

6. Yangiev A., Eshev S., Panjiev S., Rakhimov A. Calculation of sediment flow in channels taking into account passing and counter wind waves. IOP Conference Series: Materials Science and Engineering 883 (1), 012036, (2020).

7. Bazarov D., Vatin N., Obidov B., and Vokhidov O. Hydrodynamic effects of the flow on the slab of the stand in the presence of cavitation. IOP Conf. Ser. Mater. Sci. Eng. 1030, 012110 (2021).

8. S. Eshev, A. Khazratov, A Rakhimov, Sh. A. Latipov Influence of wind waves on the flow in flowing reservoirs.IIUM Engineering Journal, 21, (2), pp.125-132. (2020), DOI: https://doi.org/10/31436/iiumej.v21i2.1329. https://oi.org/10.31436/iiumej.v21i2.1329.

9. Druzhinina A.V., Borovkov V.S. Restriction on the choice of the size of the unreinforced channel in eroded soils, Hydraulic engineering, 1, pp. 47-49. (2005)

10. Bazarov D., Markova I., Norkulov B. and Vokhidov O. Hydraulic aspects of the layout of head structures during water intake from lowland rivers. IOP Conf. Ser. Mater. Sci. Eng. 1015, 012041 (2021)

11. N.I. Alekseevsky. Regularities of hydrological processes, Moscow, GEOS, p. 736, (2012)

12. Ibad - Zade Yu.A. Transportation of water in open channels, Moscow, p. 272, (1983)

13. Karasev I.F. Complexes of similarity and hydraulic resistance of self-forming river beds and canals, Hydraulic engineering, № 12, pp. 27-31, (2006)

14. Bazarov D., Markova I., Sultanov S. and Kattakulov F. Dynamics of the hydraulic and alluvial regime of the lower reaches of the Amudarya after the commissioning of the Takhiatash and Tuyamuyun hydrosystems. IOP Conf. Ser. Mater. Sci. Eng. 1030, 012110 (2021)

15. S. Eshev Sh. Latipov A. Qurbonov J. Sagdiyev M. Berdiev N. Mamatov. Non-eroding speed of water flow of channels running in cohesive soils. Innovation in construction scienceeducation (IPICSE 2020), Materials Science and Engineering 1030 (2021) 012131, (2020), doi: 10.1088 / 1757-899X / 1030/1/012131

16. Bazarov D. and Vokhidov O. Extinguishing Excess Flow Energy in Spillway Structures. In book: Proceedings of EECE 2020, LNCE 150, pp. 535-545, (2021) DOI: 10.1007/978-3030-72404-7_52

17. Kosichenko Yu.M. Study of a hydraulically advantageous profilepolygonal section of large channels and their hydraulic resistance, Prirodo obustroystvo, 2. pp.85-89, (2014)

18. LyapinV.Yu. Lyapin A.V., Doronin F.L. Features of the transfer of fine suspended matter by an uneven smoothly varying river flow. - Bulletin MGSU, 4, (2), pp. 79-84, (2010)

19. Bazarov D., Markova I., Norkulov B., Isabaev K., Sapaeva M. Operational efficiency of water damless intake. IOP Conf. Ser. Mater. Sci. Eng. 869(7), 072051, (2020)

20. S. Eshev, A. Rakhimov1, I. Gayimnazarov A. Isakov, B. Shodiev, F. Bobomurodov. Dynamically stable sections of large soil canals taking into account wind waves. Intedration, Partnership. Innovation construction science-education (IPICSE 2020), Materials Science and Engineering 1030, (2021) 10.1088 / 1757-899X / 1030/1/012131 
21. Joldassov S.K., Sarbassova G.A., Bekmuratov M.M., Zholamanov N.Z., Yangiev, A.A. New structures of sediment exclusion works.News of the National Academy of Sciences of the Republic of Kazakhstan, Series of Geology and Technical Sciences 6 (438), pp. 184189, (2019)

22. Obidov B., Vokhidov O., Tadjieva D., Kurbanova, U., Isakov A. Hydrodynamic effects on the flow elements of the downstream devices in the presence of cavitation. IOP Conf. Ser. Mater. Sci. Eng. 1030, (2021)

23. Mirtskhulava T.E. Erosion of channels and methods for assessing their stability, p. 179, Moscow, (1967)

24. Abraham D, Kuhnle R.A ., Odgaard A.J. Validation of bed-load transport measurements with time-sequenced bathymetric data. J. Hydraul. Eng. 137, pp. 723-728, (2011)

25. Yangiev A.A., Ashrabov A., Muratov O.A. Life prediction for spillway facility sidewall. E3S Web of Conferences 97, 04041 (2019)

26. Gray A.B., Pasternack G.B., Watson E.B., Warrick J.A.,Goni, M.A. Effects of antecedent hydrologicconditions, time dependence, and climate cycles on the suspended sediment load of the Salinas River, California. J. Hydrol. 525, pp.632-649, (2015)

27. Bazarov D., Markova I., Raimova I., Sultanov Sh. Water flow motion in the vehicle of main channels. IOP Conf. Ser. Mater. Sci. Eng. 883, 012025 (2020).

28. Krutov A., Choriev R., Norkulov B., Mavlyanova D. and Shomurodov A. Mathematical modelling of bottom deformations in the kinematic wave approximation. IOP Conf. Ser. Mater. Sci. Eng. 1030, (2021).

29. Matyakubov B., Begmatov I., Raimova I. and Teplova G. Factors for the efficient use of water distribution facilities. IOP Conf. Ser. Mater. Sci. Eng. 883, 012025 (2020).

30. Krutov A., Norkulov B., Uljaev F., and Jamalov F. Results of a numerical study of currents in the vicinity of a damless water intake. IOP Conf. Ser. Mater. Sci. Eng. 1030, 012121 (2021).

31. Krutov A., Norkulov B., Mavlyanova D. Simulation of spreading of non-conservative passive substances in water bodies. IOP Conf. Ser. Mater. Sci. Eng. 883(1), 012028 (2020)

32. Uralov B., Rakhmatov N., Khidirov S., Uljaev F., Raimova I. Hydraulic modes of damless water intake. IOP Conf. Ser. Mater. Sci. Eng. 1030(1), 012123 (2021)

33. Krutov A., Norkulov B., Artikbekova F., Nurmatov P. Optimal location of an intake at a reservoir prone to salt diffusion. IOP Conf. Ser. Mater. Sci. Eng. 869(7), 072020, (2020)

34. Shokirov B., Norkulov B., Nishanbaev Kh., Khurazbaev M., Nazarov B. Computer simulation of channel processes. E3S Web of Conferences, 97, 05012, (2019) 